\title{
Processos Interativos de Bebês em Creche
}

\author{
Interactive Processes among Babies at a Daycare Center
}

\author{
Kátia de Souza Amorim*, ${ }^{*}$, Adriana Mara dos Anjos $^{b} \&$ Maria Clotilde Rossetti-Ferreira $^{a}$ \\ ${ }^{a}$ Universidade de São Paulo, Ribeirão Preto, Brasil \& ${ }^{b}$ Tribunal Regional Eleitoral, Goiânia, Brasil
}

\begin{abstract}
Resumo
$\mathrm{O}$ artigo trata de estudo sobre interações de bebês com pares, que buscou apreender aspectos qualitativos desses processos relacionais, considerando particularidades dos bebês. No estudo, utilizaram-se videogravações e entrevistas, do projeto "Processos de Adaptação de Bebês a Creche", que acompanhou 21 bebês (4-13 meses) em creche. Os dados foram coletados e analisados pela perspectiva da Rede de Significações. Selecionaram-se, então, cinco episódios, a partir de três sujeitos-focais e seus pares. Análise indica ocorrência de interação, em que se destacam o papel do olhar, relações triádicas (mesmo em bebês menores de nove meses), a abreviação de recursos comunicativos e a empatia. Ainda, apesar da ausência de linguagem verbal, verificou-se ocorrência de significação. Algumas implicações teórico-práticas são apontadas.

Palavras-chave: Interação, bebê, pares de idade, creche.

Abstract

The paper presents a study regarding babies' interactive processes with peers, which aimed to apprehend some of their qualitative aspects, considering babies' peculiarities. An empirical work was conducted with video recording scenes and interviews, regarding the "Babies' Adaptation to a Daycare Center" project, which followed up 21 babies (4-13 months) at a daycare center. Data analysis was based on the Network of Meanings perspective. Five episodes are here presented regarding three focal subjects and their peers. Analysis indicates the occurrence of interactions; among them it can be highlighted the role of the glance, presence of triadic relations (even among babies younger than nine months old), abbreviation of communicative resources and empathy. Moreover, despite verbal language absence at this age, it was verified meaning processes. Some practical-theoretical implications are pointed out as well.

Keywords: Interaction, babies, peer, daycare center.
\end{abstract}

Nas últimas décadas, o Brasil tem passado por profundas transformações socioeconômicas e culturais, o que têm provocado crescente incorporação da mulher ao mercado de trabalho. Esse fato decorre da necessidade da mulher contribuir para o sustento da família, além de discursos sociais, os quais veiculam valores universalistas, igualitários e de direito de realização profissional da mulher (Romanelli, 1986; Vaitsman, 1994).

Paralela e intrinsecamente ligadas a essas transformações, alterações na organização familiar têm ocorrido, com diminuição no número de seus componentes, além de maior distanciamento físico e psicológico entre membros da família extensa e crescente número de famílias encabeçadas por uma pessoa (pai/mãe solteiro ou pais separados). A saída da mulher/mãe para trabalhar fora de casa, associada à menor rede de apoio, tem impelido a família a procurar soluções alternativas e complementares ao cuidado e à educação dos filhos, tanto no ambiente do-

\footnotetext{
"Endereço para correspondência: Departamento de Psicologia e Educação, Faculdade de Filosofia, Ciências e Letras, Universidade de São Paulo, Av. Bandeirantes, 3900, Monte Alegre, Ribeirão Preto, SP, Brasil14040901.E-mail: katiamorim@ffclrp.usp.br, adrimara@usp.br e morferre@usp.br
}

méstico (avós, vizinhas, empregadas, babás), como em instituições - escolinhas, berçários e creches (Amorim \& Rossetti-Ferreira, 1999).

No processo, a creche que tradicionalmente era vista como prejudicial ao desenvolvimento afetivo e social de crianças pequenas (Belsky, 1990), a partir de pesquisas, amplos movimentos e a elaboração de uma série de leis e diretrizes, passa a ser considerada como tendo finalidade para o desenvolvimento integral das crianças pequenas, complementando a ação da família e da comunidade (Rosenberg, 2004). A sociedade passa a reconhecer, de forma crescente, que a creche não representa um mal necessário, mas uma instituição que contribui ao desenvolvimento e à educação de crianças.

Além disso, pesquisas passaram a promover novos olhares à participação da criança pequena, mesmo de bebês, em ambientes de educação coletiva. Como discutem Darahem, Silva e Costa (2009), desde a década de 1980, pesquisadores como Rossetti-Ferreira têm lançado uma nova perspectiva à situação, de modo a apreender as especificidades do campo, levando à ruptura com a orientação de modelos de cuidados maternos substitutivos. Além disso, dada a estrutura do ambiente, o qual é composto por grande número de crianças, passaram a emer- 
gir perguntas sobre as implicações do compartilhar do bebê com outras crianças, deslocando o foco tão centrado da relação diádica adulto-criança (Rossetti-Ferreira, Oliveira, Campos-de-Carvalho, \& Amorim, 2011).

Nesse contexto, vários pesquisadores passaram a investigar relações de crianças com pares, desenvolvendo perspectivas teóricas e metodologia (Branco \& Mettel, 1995; Corsaro, Molinari, Hadley, \& Sugioka, 2003; Oliveira \& Rossetti-Ferreira, 1996; Pedrosa \& Carvalho, 2006). Nestes trabalhos, no entanto, foco preferencial era dado às interações de crianças mais velhas. Porém, o estudo da interação de bebês destacou-se como questão, pelo aumento da demanda por cuidados de crianças pequenas em instituições de educação infantil.

\section{Interação de Bebês}

O tema da interação de bebês apresenta relevância, tendo implicações não só relativas à identificação de potencialidades do bebê, como à construção de práticas diferenciadas em contextos de educação coletiva. No entanto, apesar do crescente ingresso de bebês em creche, o estudo da interação de bebês, ao longo das últimas décadas, mostrou-se limitado. E quando o assunto é colocado em pauta, a maneira de considerá-lo revelase controversa, como apontam alguns levantamentos (Anjos, Amorim, Franchi e Vasconcelos, \& RossettiFerreira, 2004; Franchi e Vasconcelos, Amorim, Anjos, \& Rossetti-Ferreira, 2003).

Estes dois trabalhos indicam que, somente uma proporção pequena de artigos trata da interação de bebês com pares (coetâneos). Ainda que, ao longo das décadas, na literatura, tem havido crescente reconhecimento das habilidades relacionais dos bebês. Essas capacidades, no entanto, têm sido investigadas a partir de variados focos, evidenciando que a área vem passando por intensas mudanças, tanto conceituais como metodológicas. Mais ainda, que os autores têm caminhado no sentido de teorização dos processos interativos, como parte de outros processos de desenvolvimento do primeiro ano de vida, como os de intersubjetividade, do desenvolvimento social e comunicativo e das relações dialógicas.

Decorrente dessas questões, vários aspectos foram considerados como importantes de serem aprofundados. Assim, buscou-se explorar se ocorrem e, em caso afirmativo, como ocorrem as regulações dos bebês com seus pares de idade. Definiu-se assim pela realização de estudos de caso, para conduzir a investigação de processos interativos de bebês com seus pares, no primeiro ano de vida, de modo a examinar qualitativamente os processos interativos, selecionando-se alguns de seus aspectos, considerando suas (in)habilidades, as formas de regulação do / pelo outro e o modo como se estabelecem as formas de "diálogo" entre eles.

\section{Método}

O presente estudo representa uma das pesquisas do grupo, que vem investigando processos relacionais (bebê- bebê, adulto-bebê) e de desenvolvimento (linguagem, olhar, emoção, etc.) de crianças nos primeiros anos de vida, em contextos específicos (casa, creche, abrigo). Como base, utiliza-se a perspectiva teórico-metodológica da Rede de Significações ([RedSig], Rossetti-Ferreira, Amorim, \& Silva, 2004; Rossetti-Ferreira, Amorim, Silva, \& Oliveira, 2008), a qual guiou a coleta e análise de dados. Trabalhando a partir dessa proposta e considerando os campos interativos como base das relações humanas, sendo estabelecidos desde o início da vida do bebê, utilizou-se a concepção de interação de Carvalho, Império-Hamburger e Pedrosa (1997).

Tal conceito engloba a noção de interação como mais do que o fazer algo juntos, contemplando a regulação recíproca, implícita e não necessariamente intencional, tratando a interação enquanto potencial de regulação entre componentes de um sistema. Os movimentos e as mudanças de comportamento de um dos componentes (no caso, bebês) só podem ser compreendidos se considerada a existência, os movimentos ou o comportamento de outros componentes (bebês/adultos), mesmo que entre eles não ocorra uma troca explícita.

No estudo em questão - processos interativos de bebês -, o referencial da RedSig contribuiu para guiar o olhar do pesquisador a resgatar o outro (no caso, o outro bebê), considerando as características das crianças, o contexto em que estão inseridos (a creche) e as práticas discursivas (Spink, 1999) que concretamente guiavam os cuidados dos bebês.

Isso nos leva a apresentar o estudo empírico, conduzido através de estudos de caso (Yin, 2005). Importante frisar que o projeto foi submetido ao Comitê de Ética em Pesquisas, tendo sido aprovado para ser desenvolvido.

\section{Processos de Adaptação de Bebês à Creche}

O material empírico foi obtido do banco de dados do Projeto Integrado "Processos de adaptação de bebês à creche", que acompanhou, ao longo de um ano, 21 bebês (4-13 meses ao ingresso), suas famílias e educadoras, em uma creche.

A direção desta creche concebe a instituição como local complementar à família e, através da organização do espaço e das atividades, busca favorecer as interações das crianças, tanto com adultos, como com outras crianças. Nesse sentido, de forma dominante, os bebês ficam sentados no chão ou em colchões, estando muito próximos de seus pares.

Dentre os vários registros da situação realizados pelo projeto, para o presente trabalho, foram utilizadas: (a) gravações em vídeo (75 horas de gravação), e, (b) entrevistas com as seis educadoras do berçário (total de 57 entrevistas).

\section{Os Bebês Participantes}

Fizeram parte do Projeto Integrado 21 bebês, que foram videogravados por três meses consecutivos. Dado o objetivo do presente estudo - apreender alguns dos aspectos qualitativos das interações de bebês com o coe- 
tâneo - e considerando o enorme volume de material, a diversidade de situações e a riqueza de possibilidades de estudo, selecionou-se, por sorteio, três sujeitos-focais: Lúcia, Helena e Marcos.

Lúcia tinha sete meses e 23 dias de idade ao ingressar na creche. Ela é miúda, magra, com olhos vivos. Apesar da pouca idade, ela engatinha e se move com bastante destreza. Segundo a educadora, "Aquele toquinho de gente... mas muito esperto ... num pára".

Helena tinha nove meses e 12 dias ao ingresso na creche. Ela tem a pele clara, cabelos loiros e olhos azuis. De início, apresenta dificuldades inclusive para se sentar sem apoio. Sua atenção está usualmente mais voltada ao que está mais próximo, atenta aos menores detalhes.

Finalmente, Marcos tem 11 meses e 21 dias de idade. Ele é um menino esguio, de olhos atentos e irmão gêmeo de Andréia, que também frequenta a creche. Segundo a educadora, "eles[os gêmeos] ficaram encantados com o espaço ... Eles ... explorando tudo".

\section{Construção do Corpus para Análise}

Após a seleção dos sujeitos-focais, mergulhou-se no Banco de Imagens assistindo às fitas uma a uma, realizando transcrição microgenética. Na transcrição, diante da idade e características dos sujeitos, privilegiaram-se, sobretudo, os elementos não-verbais como as expressões faciais / corporais e emoções que se destacavam na relação com o outro. Reassistiram-se, então, as fitas, ora em velocidade lenta, ora em velocidade acelerada, voltandose às cenas que pareciam conter algum detalhe intrigante. Após esse mergulho inicial, necessitou-se de uma reorganização menos sequencial dos processos. Passou-se assim a escolher aleatoriamente algumas fitas/cenas, alternando entre os primeiros dias de gravações, indo para o final e voltando para o meio do período, de modo a destacar dissonâncias, contrastes ou continuidades entre as imagens. A partir disso, transformaram-se os dados em mapeamentos ou descrições abreviadas dos acontecimentos.

Uma vez efetuados esses mapeamentos, complementavam-se as informações com dados das entrevistas das mães e das educadoras.

A partir desse material, analisou-se qualitativamente os processos interativos, selecionando-se alguns de seus aspectos de modo a compreender as dinâmicas das relações que se estabelecem, explicitando os recursos disponíveis para estar com as outras crianças. Ainda, análise buscou verificar os significados que vão sendo construídos conjuntamente nas situações e os modos como as crianças se posicionam nessa coconstrução de significados.

\section{Resultados e Discussão}

Vários foram os episódios interativos identificados entre os sujeitos-focais e seus coetâneos. Para o presente artigo, definiu-se pela apresentação de alguns episódios que indicam alguns dos possíveis modos de ser e se relacionar dos bebês com seus pares, no contexto específico.
Vale dizer que os episódios refletem tanto situações que ocorrem com maior frequência, quanto alguns foram selecionados pela sua raridade de aparecimento, já que destes emergem questões conceituais importantes.

\section{Primeiro Episódio: A Força e o Papel do Olhar}

Em todo o conjunto de cenas, o comportamento que se destaca é o olhar. Os bebês olham continuamente, ora ao próprio corpo, ora a objetos e pessoas próximas, ora a coisas e situações a maior distância. Essa observação por parte do bebê mostra-se bastante intensa, aparentando um rastreamento de si, do outro e do ambiente, mesmo que não haja nessa atividade uma intencionalidade, no sentido tradicional do termo, envolvendo consciência.

Análise deste olhar evidenciou que, em inúmeras situações, ele desencadeia ações no coetâneo (vocalizações, movimentos de aproximação ou afastamento do parceiro), emoções (expressão de alegria, susto ou apreensão ao se deparar com o outro a olhá-lo) ou ações semelhantes àquela que o outro realiza (como colocar ou tirar objetos de uma caixa). O olhar da criança impunha assim modificações nas ações da própria criança e de seus parceiros, desencadeando inúmeros episódios de interação propriamente dita (fazer algo conjuntamente). O olhar tinha um papel no modo de estar no ambiente e, ainda, junto aos processos de regulação das interações com os pares, como discutido por Carvalho et al. (1997).

No entanto, tanto no cotidiano de instituições creche, como na psicologia, esse dado - a frequência e o tempo com que o bebê olha ao seu redor - muitas vezes, é desvalorizado e considerado como atividade passiva e indicativa de que a criança não se engaja em atividades e relações. Os dados aqui encontrados apontam, ao contrário, para o olhar do bebê como uma atividade bastante ativa e promotora de aprendizagens e interações.

Wallon (1979) já discutia essa questão, ao afirmar que o olhar e o estado de contemplação do bebê implicam no ato de fundir-se em um espetáculo, de forma não passiva. Segundo ele, quando a criança assiste às coisas, ela está em estado de impregnação perceptivo-motor, sendo que sua musculatura trabalha durante todo o tempo em que olha. A excitação não é puramente cerebral, mas espalhase pelos músculos que são a sede de uma atividade sentida por vezes intensamente pelo sujeito, se bem que, na maioria das vezes, imperceptível para os outros. De acordo com Wallon (1979), essa impregnação compõe a função tônica muscular, que coloca o vigor e a velocidade do gesto em potência. A atividade postural, longe de se extinguir, pode resultar posteriormente na imitação.

No presente trabalho, verificou-se, mas não se quantificou, a ocorrência do olhar como recurso no papel comunicativo/relacional. Pesquisas como de Elmor (2009), por exemplo, dedicou-se a esse aspecto, realizando extensa análise quantitativa de modo a registrar os comportamentos comunicativos em bebês. Essa análise revelou o olhar como o recurso comunicativo mais frequentemente usado na relação de bebês. Belini e Fernandes (2007) também 
realizaram estudo quantitativo, identificando correlações longitudinais entre diferentes focos, direcionamento e frequência do olhar do bebê. Para as autoras também, o olhar vai além da visão, atingindo a esfera relacional.

Apontadas essas questões, o que se coloca é a necessidade de um novo olhar ao olhar do bebê, no sentido de valorizá-lo enquanto recurso de apreensão do mundo e mesmo como comunicação, não o desvalorizando enquanto atitude passiva. A noção de atividade deve ir além de esperar muita ação e movimento visíveis na criança. Porém, entende-se que, para a apreensão de maiores detalhes sobre isso, impõe-se a realização de novos estudos.

\section{Segundo Episódio: Diálogo Mudo a Oito Mãos} e Múltiplas Vozes

O episódio envolve dois bebês - Helena ( 9 meses e 13 dias) e Vera (10 meses) - e suas mães. A partir da aproximação das crianças, desenrolam-se diversas e mesmo antagônicas ações, reações e emoções entre todas elas.

Helena chega à creche no colo da mãe. Assim que entram no berçário, a mãe olha ao chão, vê Vera e a cumprimenta dizendo delicadamente "Oi!". A mãe de Vera, que está próxima, diz dirigindo-se à filha: "Alá, filha!! A coleguinha!!”. Enquanto isso, Helena é colocada no colchão, a que Vera acompanha com o olhar, enquanto balança o chocalho e balbucia (Figuras 1 e 2).

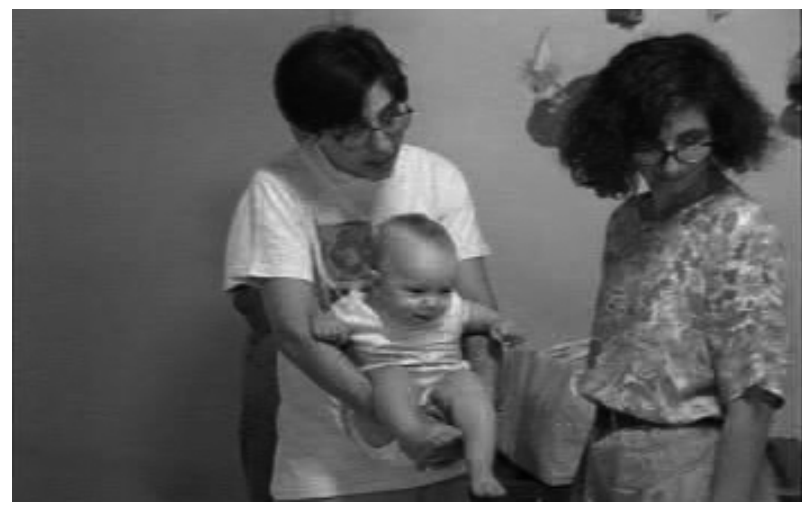

Figura 1.

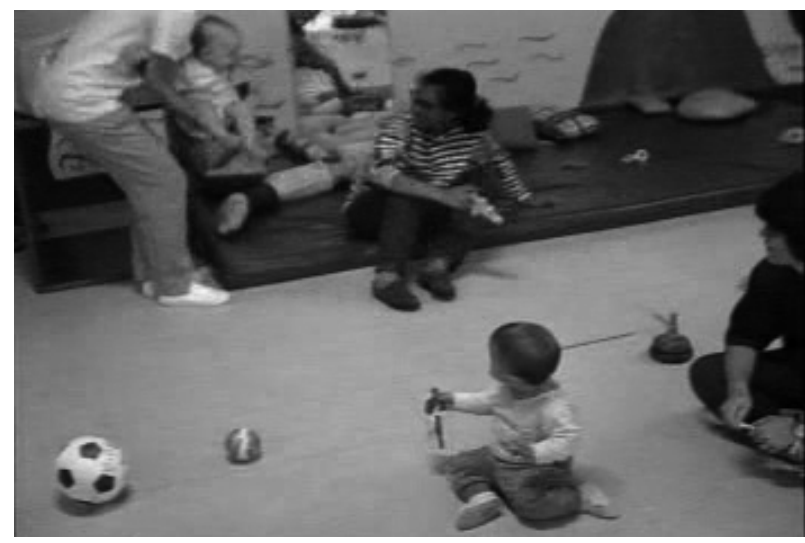

Figura 2.

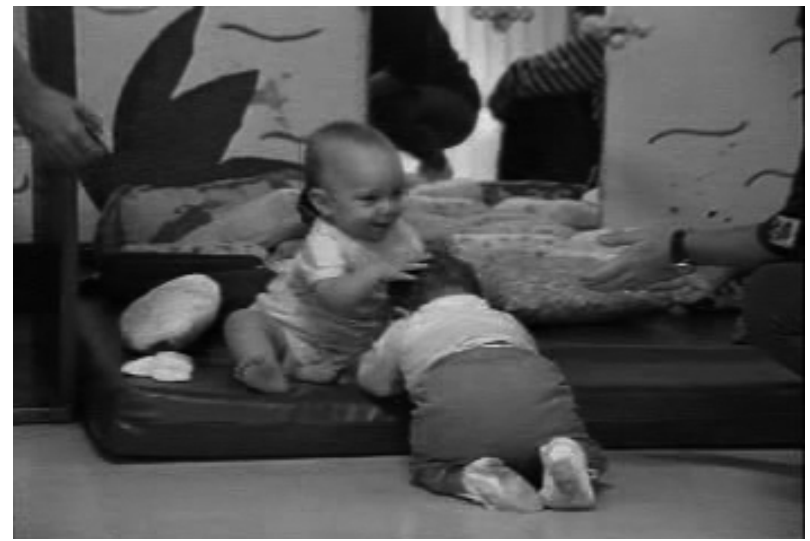

Figura 3.

Segundos depois, Vera solta o chocalho e engatinha na direção de Helena. A mãe de Vera, que se encontrava mais afastada, aproxima-se e se coloca ao lado da filha que já está diante de Helena. Esta sorri, olha para Vera e toca com as mãos sua cabeça, a que as duas mães sorriem. Nesse movimento, Vera abaixa a cabeça e as duas mães se aproximam e suas mãos ficam como que de prontidão, ao lado das duas crianças (Figura 3 ).

Helena para de tocar Vera. Em seguida, volta a tocá-la na cabeça. Vera afasta-se vocalizando "Ai, ai...", enquanto olha à mãe. Depois, Vera olha para Helena que, sorrindo, sacode as mãos fortemente, na direção de Vera, batendoas em sua cabeça. Nesse momento, a mãe de Vera pergunta se a filha não vai fazer carinho em Helena; simultaneamente, a mãe de Helena segura na mão da filha dizendo: “Carinho...!!" E, segurando-lhe a mão, passa a mão de Helena no rosto de Vera (Figura 4), gesto que Helena repete depois, sem auxílio.

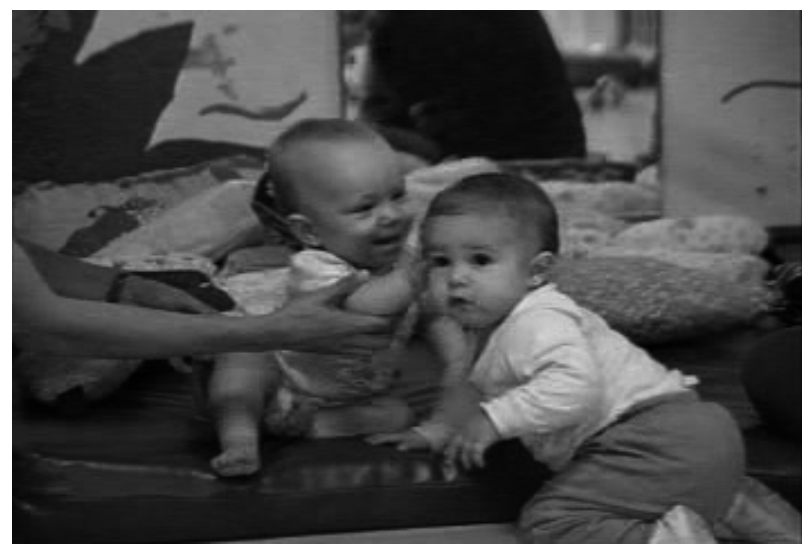

Figura 4.

Neste movimento, Helena esbarra a mão no olho de Vera que abaixa a cabeça, afasta-se e esfrega o olho. Depois, olha para a mãe e vocaliza (“Aaaa...") com expressão bastante séria. A mãe de Helena segura a mão da filha, enquanto a educadora Mirela diz: "É, carinho na amiga!!”. Vera volta a olhar Helena e toca o rosto 
dela também. Helena, não mais sorrindo, pisca os olhos e olha para Vera. Rapidamente, a mãe de Vera segura as mãos da filha, enquanto que a mãe de Helena diz: "É, tem que devolver também". Helena sacode agitadamente as mãos e acaba tocando novamente nos olhos de Vera que olha para Helena e para a mãe de Helena, balançando todo o corpo, vocalizando firme, enquanto leva sua mão novamente na direção de Helena. A mãe de Vera diz "Machuca!". A mãe de Helena retira a filha do colchão e se afasta, a que Vera acompanha com o olhar (Figura 5).

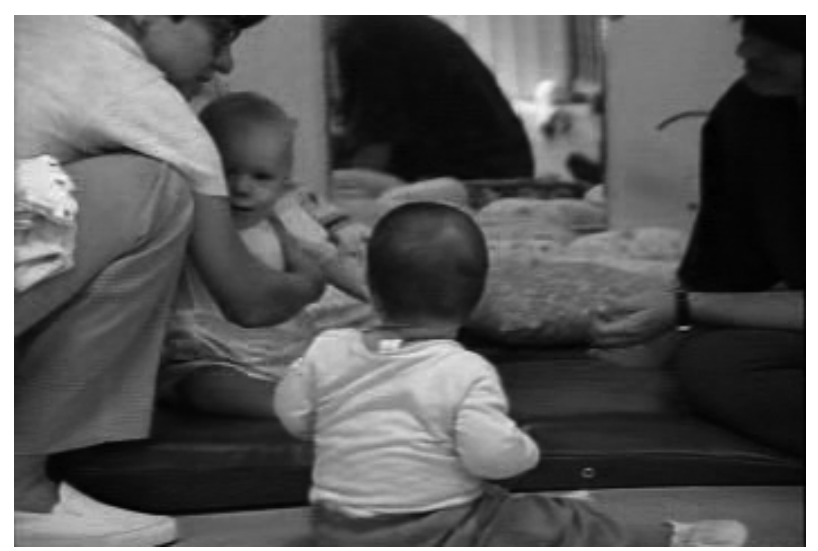

Figura 5.

No episódio, fica evidente que, em um primeiro momento, o interesse pela outra criança é marcante, apesar de se entender que essa atenção ao parceiro foi, inicialmente, mediada pelas mães. Após o encontro, a mediação pelo adulto continua, dando-se através de um jogo/ dança de mãos e por falas (É o nenê! Ó, machuca! Carinho!, etc.), que vão dando a tessitura cultural à situação do encontro. Ora reforçam a aproximação, ora buscam precaver o contato, manipulam a mão da criança para transformar o gesto em significativo de carinho e não de agressão, afastam as crianças uma da outra.

Mas o adulto não é o propulsor desta história. Ele acompanha e ajuda a significar a situação de um encontro que se efetiva pela própria ação das crianças. $\mathrm{O}$ interesse de uma pela outra é visível pela fixação do olhar na outra, pela expressividade que irradia através dos sorrisos e movimentos corporais agitados, sendo que uma das crianças inclusive se desloca, engatinhando na direção da outra. A emoção como que contagia, liga, atrai, como discute Wallon (1979), levando os dois bebês a ficarem frente a frente.

Talvez facilitada pela posição de estar sentada e em local mais alto que a outra (considerando o desnível entre o colchão e o chão), Helena realiza com mais intensidade e frequência movimentos agitados de braços, movimentos que se configuram como toques na cabeça de Vera. Porém, esses gestos adquirem significados diversos para os adultos, ao longo do tempo, significados estes que orientam suas ações e que, possivelmente, interferem nas ações e significações das crianças. Já para as crianças, em um primeiro momento, os gestos representam expressividade emocional de alegria; em outro, expressão de carinho; posteriormente, de agressão ou perigo de machucar. E esses múltiplos significados aparecem não só expressos nas verbalizações dos adultos, mas também na dança de suas mãos que se posicionam de maneira a orientar a ação da criança, protegê-la ou impedir que algum dano the aconteça; por sua vez, os próprios bebês inicialmente sorriem ao outro; depois, emitem tom incomodado e buscam pelo adulto; ou revelam expressões faciais de seriedade e tensão.

As crianças se utilizam de recursos corporificados (Amorim \& Rossetti-Ferreira, 2008; Fernández-Abascal, Sánchez, \& Montañés, 2009; Fogel, 1992), nesse dialógico interjogo de movimentos, gestos, sons, emoções, falas, balbucios, sorrisos, protestos, (co)construindo, (trans)formando e (re)negociando significados. Como Costall (1995) afirma, o significado não representa uma adição psíquica, mas é algo que existe na relação ser humano - ambiente. Nesse processo, em função das novas ações dos parceiros, o curso das ações, emoções, dos papéis assumidos / atribuídos / recusados e a própria interação vai sendo modificada na dinâmica que aqui envolve as crianças e também os adultos.

\section{Terceiro Episódio: O Complexo Criança-Objeto}

O episódio envolve Helena ( 9 meses e 12 dias), Lúcia (7 meses e 23 dias) e suas mães. Ele apresenta a alternância sucessiva do foco de interesse de cada uma das crianças, em função dos objetos que a outra criança pega ou manipula.

Helena está sentada no colchão, ao lado de sua mãe, mexendo em um telefone de brinquedo. Lúcia está sentada próxima, apesar de fora do colchão. Ao redor das duas existe grande quantidade de objetos (Figura 6). Lúcia olha para Helena / telefone e engatinha nessa direção. Ao aproximar-se, apóia-se no colchão e tenta subir nele, sem sucesso. Lúcia ajoelha-se e observa Helena, que mexe no telefone. Enquanto isso, Lúcia mexe em uma cobra de pano que está à sua frente, levando-a à boca. A mãe de Lúcia fala para a filha tirar a cobra da boca (Figura 7). Nesse momento, Helena vira-se e olha na direção da mãe de Lúcia e depois para Lúcia (Figura 8). Como a cobra é longa, parte dela encontra-se próxima a Helena e ela também passa a mexer na mesma cobra. Enquanto mexe, Helena vê no colchão o objeto no qual Lúcia mexia antes. Helena inclina-se na direção do objeto, mas não consegue pegá-lo. 


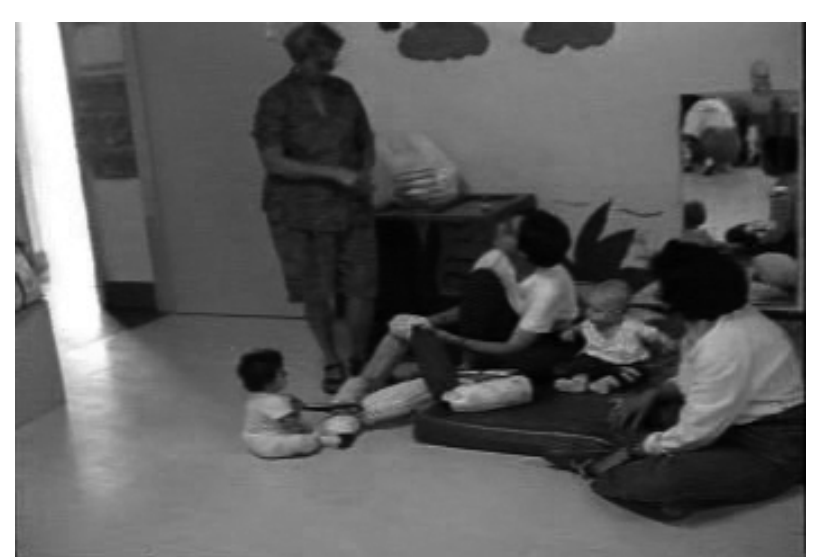

Figura 6.

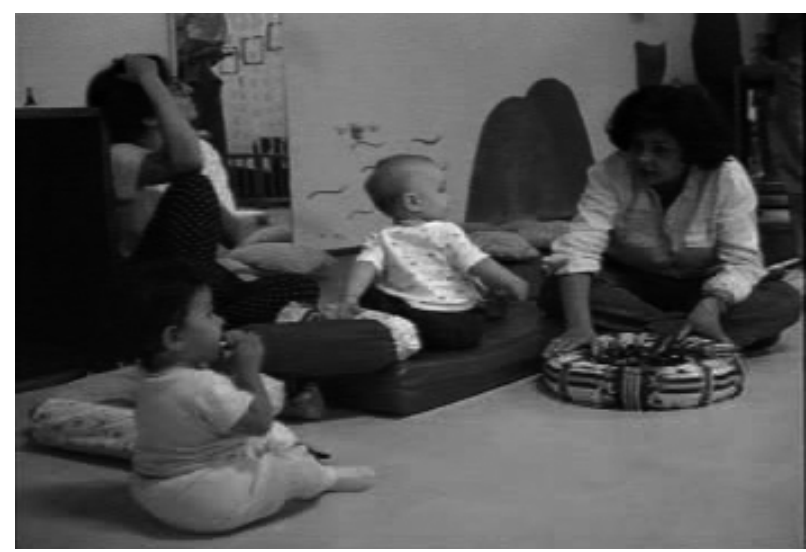

Figura 7.

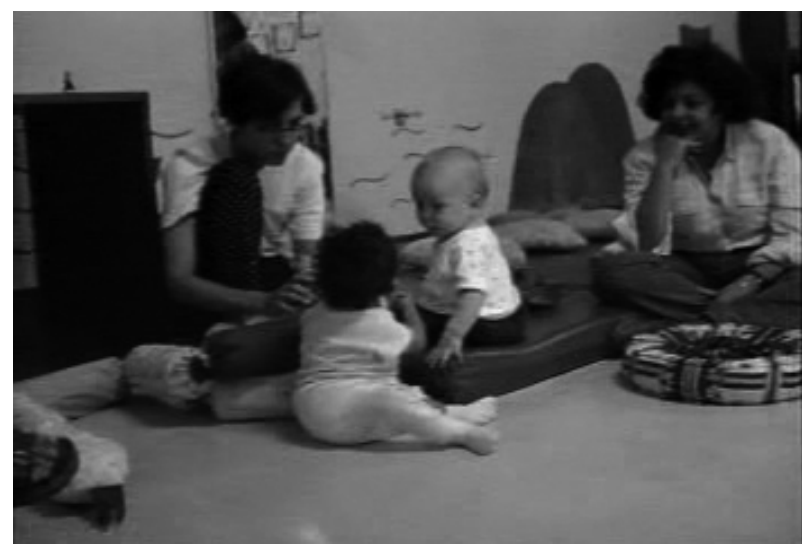

Figura 8 .

Lúcia engatinha na direção da mãe, arrastando a cobra junto. Esta cai de sua mão. Helena observa e leva sua mão até a cobra, mas não a alcança. Lúcia para e, novamente, pega a cobra. Senta-se ao lado de Helena, porém de costas para ela (Figura 9). Nesse momento, a mãe de Helena pega um boneco com guizo, mexendo-o na frente da filha, que o olha. Lúcia vira o corpo e olha na direção de Helena, sua mãe e do boneco. Simultaneamente, ba- lança o corpo e vocaliza. Helena observa Lúcia e leva sua mão na direção dela.

A mãe de Lúcia chama a filha, apontando para a estante no outro lado da sala, onde há outros objetos. Lúcia olha para a mãe e depois na direção da estante. A mãe de Lúcia pega então um telefone (o que estava com Helena) e o bate no chão. Lúcia sorri, indo em direção à mãe. Simultaneamente, Helena se vira e olha para o telefone. Helena olha Lúcia aproximar-se, pegá-lo e mexer nele. A educadora Mirela aproxima-se com outro telefone igual e o dá à Helena, a que sua mãe diz: "Ela ficou olhando como se tivessem pego o dela" (Figura 10).

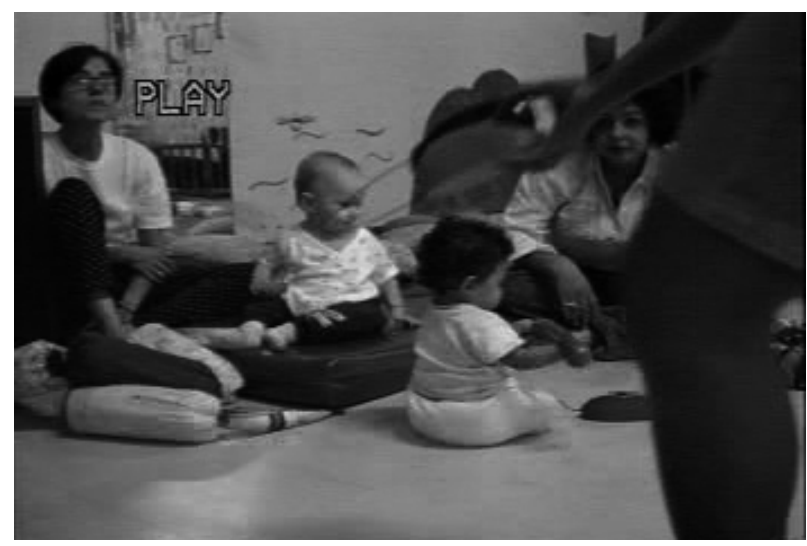

Figura 9.

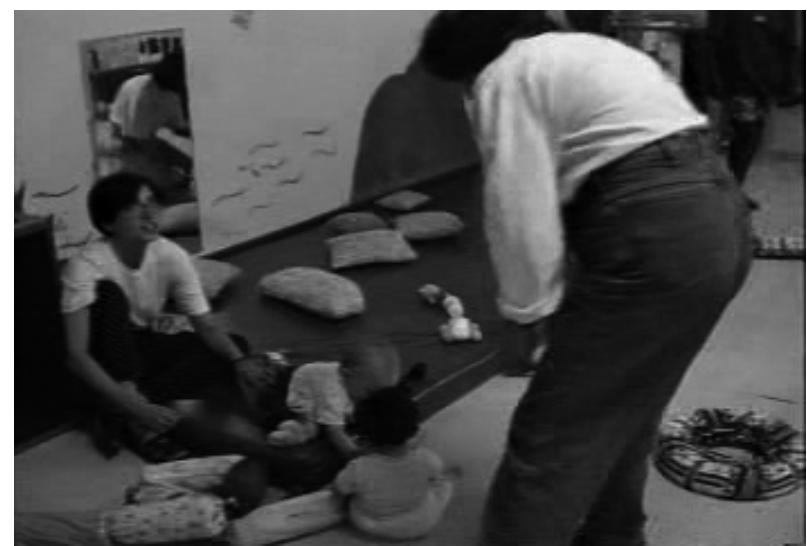

Figura 10.

Esse episódio mostra-se bastante comum nos processos interativos observados, em que, apesar de existir um grande número de objetos disponíveis, somente alguns figuram como atrativos, sendo que outros não despertam interesse. Repetidamente, as crianças têm a atenção e o interesse direcionados ao objeto que a outra criança manipula. No caso, ora Lúcia se interessa pelo telefone nas mãos de Helena, ora Helena pelo telefone nas mãos de Lúcia; ora Helena dirige seu olhar à cobra de pano nas mãos de Lúcia; ora Helena olha ao objeto com guizo, nas mãos de Lúcia, ora o inverso. Porém, no entretempo, em 
função de outros eventos, os mesmos objetos não lhes interessam mais.

Para os adultos, esses movimentos parecem representar processos de disputa, o que reiteradamente os leva a dar objetos semelhantes a cada uma das crianças. No entanto, os objetos constituem sim atrativos, mas não se pode dizer que o comportamento seja regulado unicamente pela atração pelos objetos em si. O são muito mais quando estão sendo manipulados pela outra criança que, ao manipular, mover, chupar, jogar, chacoalhar, etc., lhes dá movimento. A atração se dá pelo complexo bebê-objeto. Nos movimentos, fortuitos ou não, esse complexo promove encontros entre as crianças que se dão, fundamentalmente, através da posição do corpo de uma em relação à outra, da orientação visual, dos sons gerados pela outra criança ou pelos adultos que se dirigem e/ou que se referem à criança. Ainda, verifica-se que os encontros ocorrem através de orientação comum da atenção de ambas, fazendo com que a ação de uma seja modificada pela e/ ou modifique a ação da outra.

No caso, importante destacar que, através desse jogo de alternância de atenção conjunta, verificou-se o estabelecimento da relação triádica (bebê-bebê-objeto), a qual é observada aqui em bebês de sete e nove meses de idade. Esse dado aponta não só para a precocidade desse processo, como à sua maior amplitude. Tal questão merece atenção, pois Tomasello (2003) propõe que, mais ou menos aos nove meses, ocorre uma revolução sociocognitiva, quando os bebês pela primeira vez começam a olhar, de modo flexível e confiável, para onde os adultos estão olhando. Segundo o autor, esse compartilhamento da atenção revela um marco no desenvolvimento do bebê: ele agora se percebe capaz de também monitorar, pelas pistas visuais, a atenção e o comportamento do adulto.

Marcante em nossas observações, é que vimos a relação triádica ocorrer em uma criança de sete meses de idade. Ainda, verificamos esse comportamento não só em idades bem mais precoces, como não apenas na relação com o adulto, mas envolvendo também interações com pares (coetâneos).

Quarto Episódio: Interação com o Par de Idade, sendo este o Irmão Gêmeo

Nesse episódio, estão envolvidos os irmãos Andréia e Marcos (de 11 meses e 21 dias), além da mãe e educadora. Ele evidencia o quanto que a comunicação e negociação entre os irmãos se faz de maneira bastante ágil e fluida.

Mãe e educadora chegam com as crianças no colo e as colocam no chão, um próximo ao outro (Figura 11). Ao sentar, Andréia pega um cavalo. Marcos, imediatamente, sem olhar para a irmã, leva suas mãos ao cavalo e puxao. Mas, este escorrega e permanece com Andréia (Figura 12). A educadora Mirtes se aproxima e dá outro cavalo igual para Marcos. Andréia olha para o lado, deixa seu cavalo e sai engatinhando.

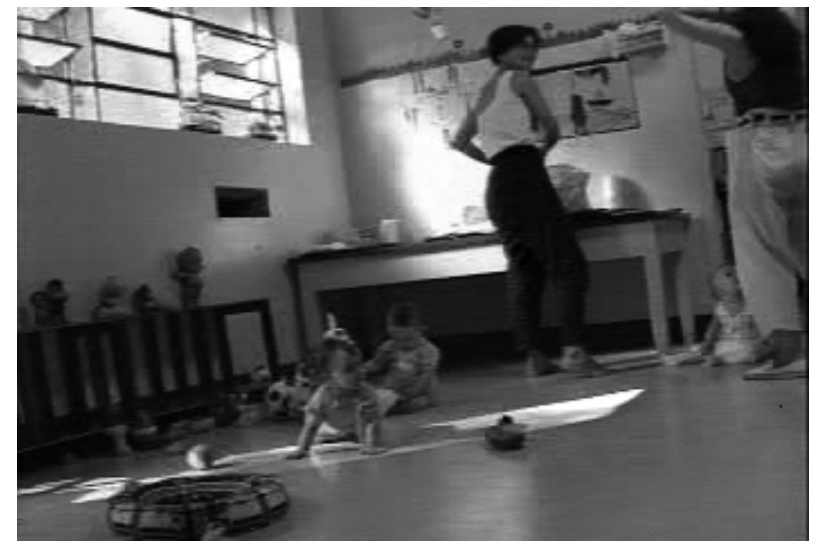

Figura 11.

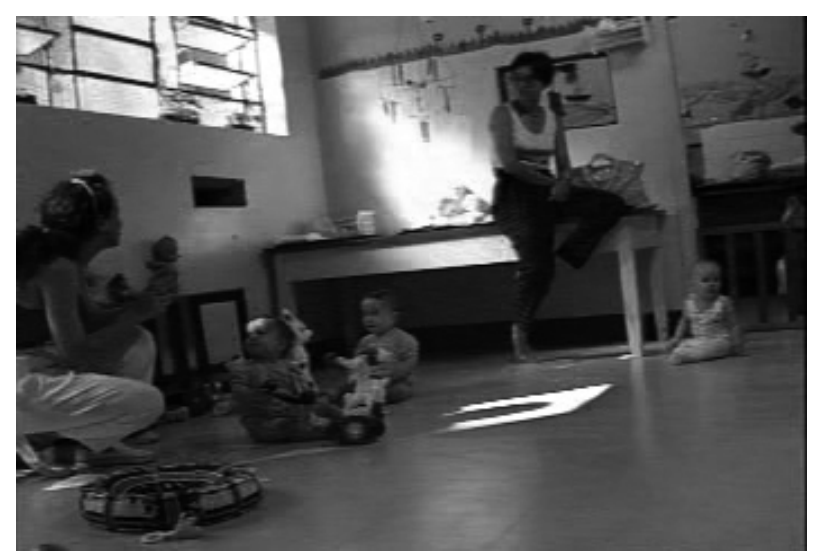

Figura 12.

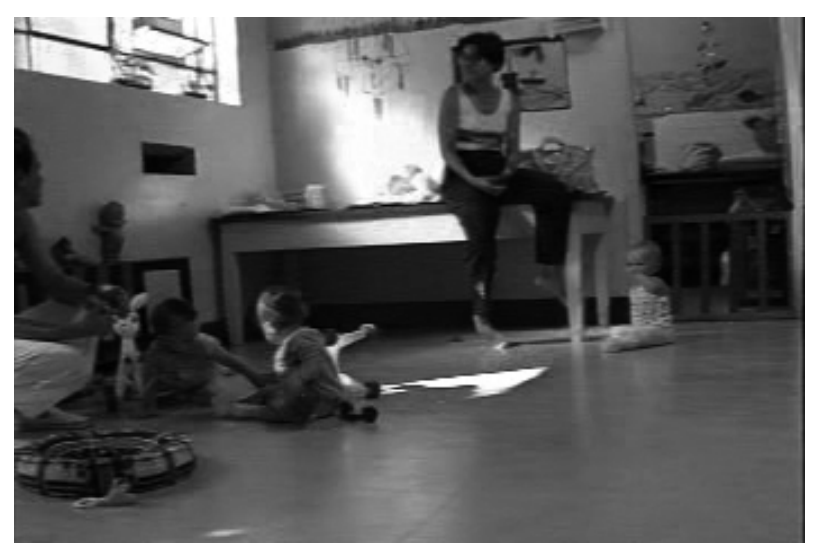

Figura 13.

Marcos observa Andréia. Nesse momento, a mãe se aproxima de Andréia e lhe entrega um telefone. Andréia, que estava engatinhando, senta-se e mexe no telefone. Depois, Andréia volta a engatinhar na direção de chocalho que está próximo, pegando-o. Andréia senta-se e, com o chocalho em uma das mãos, pega o telefone. Marcos se aproxima, sentando-se de costas para Andréia. Pouco depois, Marcos vira-se e olha para a mão da irmã e vê o chocalho. Em posição de engatinhar, ele leva sua mão ao 
Amorim, K. S., Anjos, A. M. \& Rossetti-Ferreira, M. C. (2012). Processos Interativos de Bebês em Creche.

chocalho. Andréia imediatamente olha para a mão do irmão, larga o telefone e busca virar o corpo (Figura 13). Marcos senta-se, tendo o chocalho na mão. Andréia solta o telefone e pega o chocalho com a outra mão. Nesse movimento, ao girar o próprio corpo, ela vê o cavalo com as rodinhas. Marcos olha para o chocalho que está em suas mãos. Andréia pega o cavalo. Marcos olha para a irmã. Depois, Andréia larga o cavalo e inclina-se para o outro cavalo que está à frente do irmão, aproximando-se dele. Ela leva sua mão ao cavalo à frente do irmão e, a seguir, ao chocalho. Marcos, de cabeça baixa, olha de soslaio para a irmã / chocalho, puxando-o e segurando-o. Andréia olha para o irmão / chocalho, depois para o lado e pega novamente o telefone. Marcos olha para o lado e engatinha em outra direção.

O que se destaca nesse episódio é o modo de agir dos dois irmãos. Diferentemente dos episódios anteriormente discutidos, o modo de negociação entre as duas crianças difere do conjunto de crianças naquele espaço, particularmente no início da frequência a creche. Aqui, há uma díade formada por gêmeos de quase um ano que, desde que nasceram, cotidianamente, passam o dia na companhia do outro e, normalmente, são colocados próximos ao outro. Com isso, nas relações e comunicações entre eles, não aparece o que se vê no estabelecimento inicial das interações das outras crianças: não há observação prolongada do outro, negociação quanto à tomada do objeto e observação da reação do outro. O pegar objetos do outro não é reticente, mas direto, sem a realização de muitos movimentos corporais e expressividade emocional. Verifica-se rapidez e, praticamente, ausência de olhar que coordene a atenção.

A interpretação é de que, pelo fato de serem irmãos gêmeos e de terem íntimo e contínuo contato, há entre eles ajustamento mútuo de comportamento e de comunicação. Isso leva a considerar a noção de abreviação, como proposto por Lyra (2000). Para a autora, o ajustamento mútuo seria observado em situações de trocas de curta duração executadas pela díade de forma rápida e fácil, nas quais elementos anteriormente trabalhados de forma mais extensa aparecem de modo abreviado.

A autora usa esse modelo para compreender o processo de comunicação mãe-bebê. Porém, ela própria (Lyra, 2007) aponta a outras possíveis aplicações deste modelo, sendo um deles para investigar outros tipos de parceiros e comunicação. Entende-se que esse processo, no primeiro ano de vida, poderia ser então considerado em interações de bebês, desde que haja maior regularidade nas suas relações. Essa hipótese foi verificada como positiva em estudo de C. A. Costa (2008), que acompanhou longitudinalmente interações de bebês.

\section{Quinto Episódio: Ajudando e Consolando - Empatia em Criança de Um Ano de Idade}

Desse episódio, participam o bebê Lúcia ( 8 meses e 28 dias) e Dirceu (14 meses e 4 dias), além das educadoras Zilda e Mirtes. Ele apresenta o desconsolo de Lúcia que procura, sem sucesso, por sua educadora e a busca por consolo e resolução da situação por Dirceu.

Na situação, Lúcia parece ter tido algum contratempo e chora fortemente, engatinhando atrás da educadora (Figura 14). Seu choro é tão forte, que outros bebês olham para ela. Porém, a educadora realiza outra atividade, pegando Helena no colo, levando-a ao dormitório. Quando a educadora entra no mesmo, fecha a porta atrás de si.

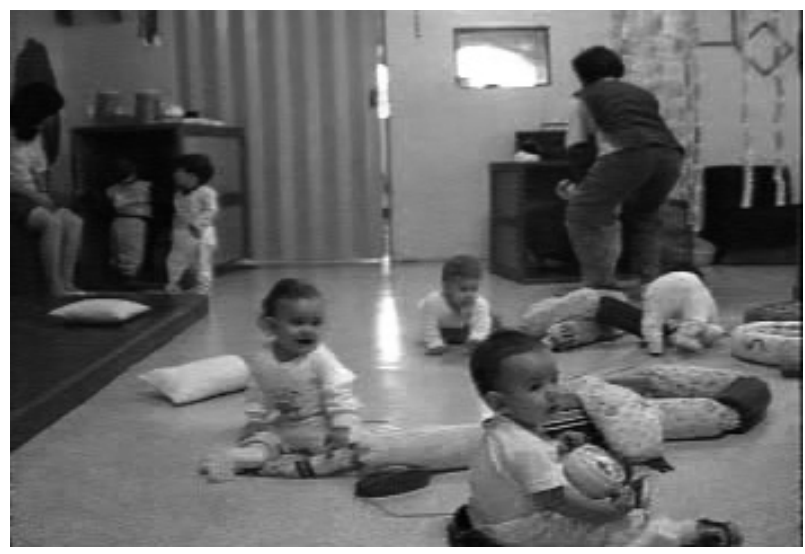

Figura 14.

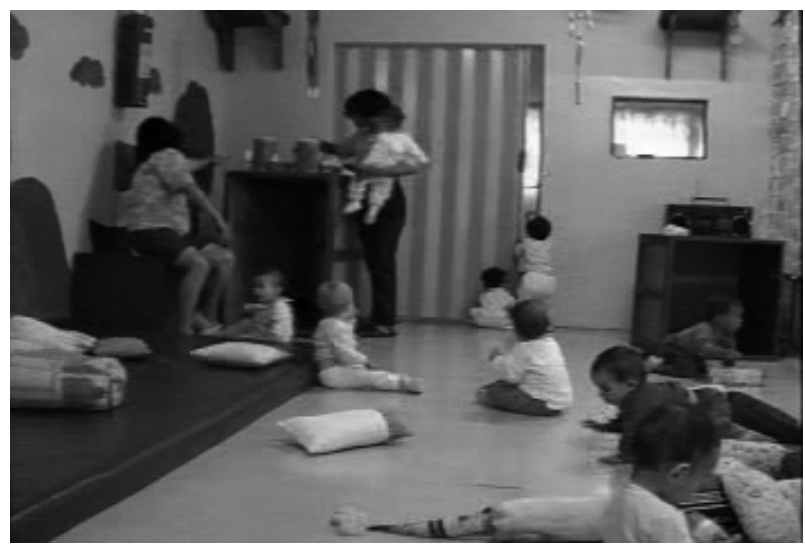

Figura 15.

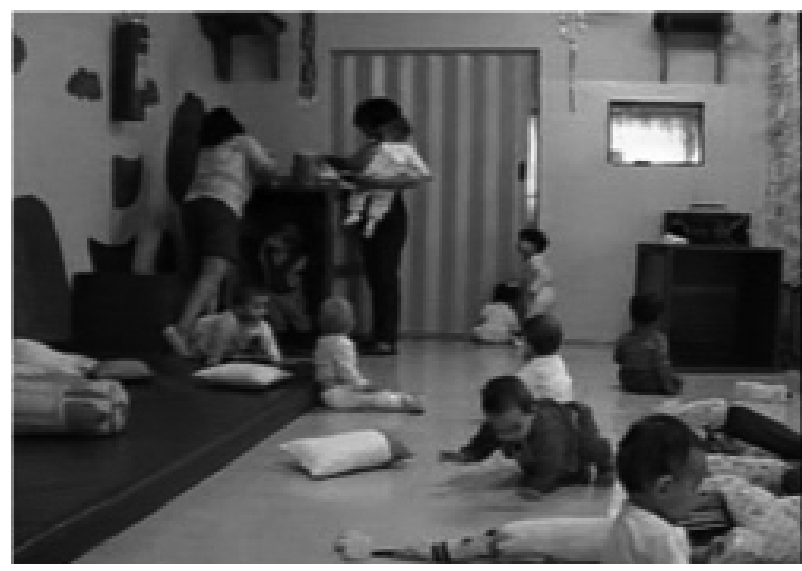

Figura 16. 
Lúcia a chorar segue a educadora, engatinhando até a porta do dormitório. Chega à porta, senta-se e tenta abrila, sem sucesso, o que faz com que seu choro se intensifique. Dirceu, que se encontra próximo, dirige-se à porta e a força no sentido de abri-la, também sem sucesso (Figura 15). Ele olha à sua volta. A menina continua sentada ao pé da porta, chorando. Ele toca, então, delicadamente a cabeça de Lúcia, dando-lhe três leves toques (Figura 16). Após alguns segundos, Dirceu tira as mãos da cabeça de Lúcia e dirige-se a outra educadora, próxima aos dois. Ao chegar a ela, puxa a barra de sua calça (Figura 17). A educadora, porém, está ocupada, preparando uma mamadeira e não olha para Dirceu que, novamente, mexe em sua calça. Sem resposta, Dirceu vira-se e volta à porta, onde Lúcia ainda se encontra. Ele mexe mais algumas vezes, fazendo força para abri-la, sem sucesso. Olha ao redor e afasta-se dali. Após alguns segundos, a educadora sai do dormitório, vê Lúcia e a pega no colo, a criança parando de chorar (Figura 18).

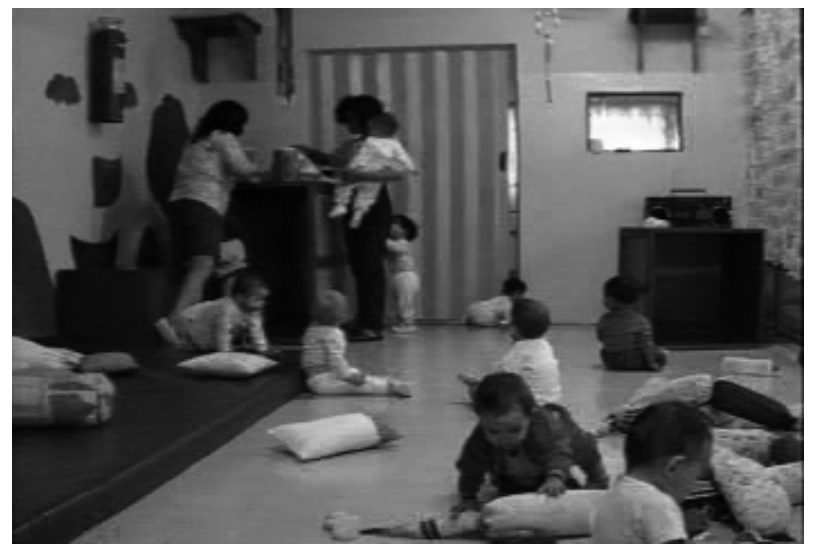

Figura 17.

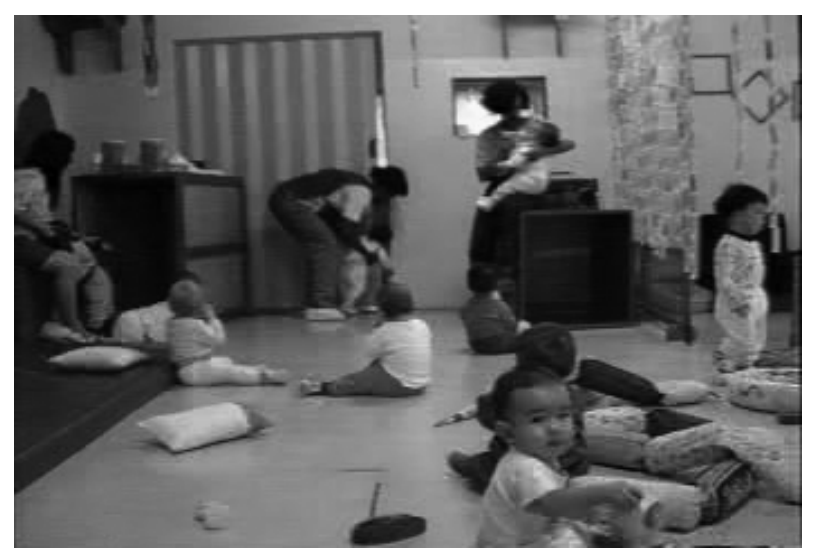

Figura 18.

Este episódio evidencia que, apesar da tenra idade -9 e 14 meses -, ambas as crianças já agem para além do contexto social imediato. Lúcia (9 meses) procura de maneira bem localizada pela educadora, mesmo quando ela desaparece do seu campo visual. Orientada, ela mantém sua meta de encontrá-la, apesar das inúmeras pessoas (adultos e crianças presentes) e da educadora ter fisicamente desaparecido. Por outro lado, Dirceu demonstra um grau significativo de independência da própria situação imediata pois, apesar dele não ter experienciado a situação que levou ao desconforto de Lúcia e só perceber que a menina deseja entrar no dormitório, a partir do choro intenso dessa última, Dirceu se identifica com sua aparente angústia, assumindo sua perspectiva e agindo em prol dela. Dirceu, com seus 14 meses de vida, adota a perspectiva de Lúcia buscando não só resolver o problema do bloqueio de acesso da menina à educadora (tentando abrir a porta e indo buscar ajuda de adultos, quando ele próprio não consegue abri-la), como buscando acalmá-la (através do gesto de consolo). Dirceu regula seu comportamento através do comportamento de Lúcia, o que nos leva a considerar aqui o comportamento de empatia.

Tradicionalmente, falar em empatia significa em se verificar uma resposta afetiva vicária a outras pessoas, ou seja, uma resposta afetiva apropriada à situação de outra pessoa e não à sua própria situação. Mas, como discutir a empatia nessa idade, se a maioria das definições distingue dois níveis nesta dimensão psicológica: (a) capacidade afetiva para compreender e partilhar sentimentos dos outros, e, (b) capacidade cognitiva para compreender pontos de vista e perspectivas alheios.

Coelho e Figueiredo (2004), por exemplo, ao discutir a obra de Freud no que se refere à empatia, indica que, para este autor, a pergunta por detrás do tema (e do complexo campo da intersubjetividade) pode ser resumida em "Como é possível conhecer um outro?" Ou até, "O outro existe ... ou só possui existência a partir da consciência que possuo dele?". E essas perguntas são formuladas já que para Freud, assim como Piaget e outros, as crianças pequenas não seriam capazes, cognitivamente, de responder a emoções de outros, uma vez que se encontram em autismo normal ou em uma fase de atitude egocêntrica.

Contrapondo-se a essas perspectivas, Bussab, Pedrosa e Carvalho (2007) apresentam episódio semelhante envolvendo dois bebês, um de nove e outro de 13 meses de idade, em ambiente de creche. Como as autoras discutem, apesar de pouco frequente, esse tipo de episódio levanta questões teóricas intrigantes, com implicações em termos de concepções sobre a criança, o desenvolvimento e a natureza da sociabilidade humana.

Gillespie (2010), também ao discutir a questão da empatia, afirma que o ser humano é um ser ativo que vai além da situação imediata, sendo motivado por questões que envolvem preocupações pelo outro. Nesse processo, para o autor, elemento central é a intersubjetividade, com a integração de perspectivas que são complementares, mas não equivalentes. Apesar de Dirceu assumir a perspectiva da outra criança, isso não o coloca na mesma posição 
(tanto que, apesar dele não ter resolvido a situação, ele se afasta sem sofrimento). O que há é uma integração, o que implica em manter a própria perspectiva, enquanto se assume a perspectiva alternativa e distinta do outro. Para a compreensão do processo, o autor discute a "troca de posições", em que a vida social é pensada como tendo uma estrutura em termos de posições sociais distintas, apesar de complementares, envolvendo distintas perspectivas motoras e/ou perceptuais e papéis sociais que levam a expectativas do que cada parceiro deve fazer na interação. O mecanismo de integração entre os dois não é mental, mas o de uma ação social.

Este episódio fortalece a discussão de que, mesmo em tenra idade, tem-se uma percepção interpessoal. Nesse sentido, trabalhos como de Trevarthen (1993), ao tratarem da intersubjetividade inata, tratam a empatia não enquanto bem cultural aprendido, mas como algo que pode se manifestar desde o nascimento. Como os diferentes autores afirmam, quando se desloca o foco da cognição para a ação ou para o aspecto afetivo-emocional, o fenômeno da empatia passa a fazer sentido e se torna reconhecível na criança pequena. Essas questões são aqui apenas apontadas e ensejam novos estudos para seu aprofundamento.

\section{Comentários Finais}

Concluindo, apesar de que com isso o que se faz é abrir uma série de outras e intrigantes questões, serão pontuados de forma bastante breve alguns aspectos observados e discutidos da interação de bebês com seus pares.

Interações de bebês foram verificadas de forma bastante frequente e significativa, mesmo entre bebês de bem tenra idade. Essa observação pode ter sido possibilitada pelo fato das pesquisadoras assumirem um referencial que se afasta de propostas que tomam o adulto (oral, verbal) como padrão de medida do ser criança; que se afasta de propostas que projetem na criança a representação do ser adulto (Carvalho, 1983). Como afirma Pino (2005), entre adultos e crianças não existem apenas semelhanças, mas também diferenças, e estas traduzem a peculiaridade da condição de ser criança e não algo negativo dessa condição. Isso impõe investigar a situação, buscando apreender as peculiaridades de ser dos bebês.

Nesse sentido, reiteramos as particularidades dos modos de interação e relação entre pares de bebês, já apontados nos trabalhos de Anjos et al. (2004) e Franchi e Vasconcelos et al. (2003). A interação se dá de maneira fluida e breve, apesar de que o acompanhamento longitudinal evidencia que os bebês retomam, posteriormente, elementos anteriormente vivenciados e negociados pelas díades.

Os processos interativos são intensamente mediados pelo adulto e pela organização do ambiente. No caso, a maior possibilidade de contato com o par, desdobrando uma série de eventos interativos, relaciona-se ao fato de que, nessa creche, os bebês são colocados no chão ou colchão, permanecendo próximo aos outros. Ainda, os bebês são concebidos como capazes de estabelecimento de interação não só com o adulto, mas também com coetâneos.

Esses processos aqui apreendidos talvez não tivessem a mesma visibilidade ou mesmo possibilidade de ocorrência em situações em que o ambiente fosse organizado com berços com grades. Podem não ser apreendidos também, em contextos em que se espera que os bebês fiquem em casa, sob os cuidados direto das mães (Morett, 2007). É raro de serem vistos também em países em que a licença maternidade é de um ano (como em países nórdicos), onde os bebês só são cuidados coletivamente, após completarem seu primeiro ano de vida. Como Overton (1997) discute, o significado dessa ou daquela interação para um sistema vivo não é dado de fora, mas representa o resultado da organização e história desse sistema.

Nos processos interativos propriamente ditos, elemento que se mostrou chave foi a força e o papel do olhar, que tem papel significativo como recurso comunicativo, dada a sua riqueza de expressão. Isso coloca a necessidade de um novo olhar ao olhar a essa faixa etária.

Nos processos interativos, verificou-se que, apesar da idade das crianças (em que ainda não fazem uso de pensamento e fala verbais), elas agem para além do contexto social imediato. Ainda, tais eventos resultavam na coconstrução de significados através das ações e reações das crianças. Como numa dança, com encontros e desencontros, os significados coconstruídos na dinâmica dos acontecimentos emergem nas situações, apesar de ou graças à participação dos adultos, mas também por parte das crianças que se colocam como participantes ativos na relação com o outro. Essas atribuições de significados são coconstruídas e comunicadas através dos gestos, do olhar, da postura corporal, do choro, dos sorrisos, das vocalizações e das emoções. Nos entrelaçados processos, um e outro se envolve e transforma as (re)ações do outro.

Ainda, verificou-se que as interações envolvem um jogo de atenção conjunta, com a ocorrência de relações triádicas. Esses dados indicam que as relações triádicas apresentam possibilidades de se manifestar em bebês mais novos e, ainda, na relação com coetâneo.

A análise revelou também que o processo de comunicação entre pares pode seguir o modelo usualmente atribuído à interação com adultos em que, com o desenrolar da relação, ocorre abreviação de recursos de comunicação na relação com o outro.

Finalmente, comportamentos de empatia foram observados em uma idade não esperada, em contrapartida ao que tradicionalmente é discutido na literatura. A consideração das especificidades das crianças, com deslocamento do olhar do pesquisador de processos cognitivos, para ações e aspectos afetivos, permite que se atente à sua ocorrência em tenra idade. 
A análise do material indica que contextos e referenciais teóricos que destaquem nova maneira de conceber os bebês em sua especificidade, aliada a esforços no sentido de aperfeiçoar procedimentos de análise, podem apreender surpreendentes competências do bebê e sua constituição. Esses dados exigem, no entanto, novas investigações para seu aprofundamento.

\section{Referências}

Amorim, K. S., \& Rossetti-Ferreira, M. C. (1999). Creches com qualidade para a educação e o desenvolvimento integral da criança pequena. Psicologia: Ciência e Profissão, 19(2), 6469.

Amorim, K. S., \& Rossetti-Ferreira, M. C. (2008). Corporeidade, significação e o primeiro ano de vida. Arquivos Brasileiros de Psicologia, 60, 67-81.

Anjos, A. M., Amorim, K. S., Franchi e Vasconcelos, C. R., \& Rossetti-Ferreira, M. C. (2004). Estudo de processos interativos de bebês. Estudos de Psicologia (Natal), 9(3), 513-522.

Belini, A. E. G., \& Fernandes, F. D. M. (2007). Olhar de bebês em desenvolvimento típico: correlações longitudinais encontradas. Revista da Sociedade Brasileira de Fonoaudiologia, 12(3), 165-173.

Belsky, J. (1990). The "Effects"of Infant Day Care Reconsidered. In N. Fox \& G.G. Fein (Eds.), Infant Day Care: The current debate (pp. 3-40). Norwood, NJ: Ablex.

Branco, A. U., \& Mettel, T. P. L. (1995). O processo de canalização cultural das interações de criança na pré-escola. Psicologia: Teoria e Pesquisa, 11(1), 13-22.

Bussab, S. R, Pedrosa, M. I., \& Carvalho, A. M. A. (2007). Encontros com o outro: Empatia e intersubjetividade no primeiro ano de vida. Psicologia USP, 18(2), 99-132.

Carvalho, A. M. A. (1983). O desenvolvimento da criança. Pediatria Moderna, 18(5), 269-280.

Carvalho, A. M. A., Império-Hamburger, A., \& Pedrosa, M. I. (1997). Interaction, regulation and correlation: A conceptual discussion and empirical examples in the context of human development. In M. Lyra \& J. Valsiner (Eds.), The construction of psychological processes in the course of interpersonal communication (pp. 135-151). Norwood, NJ: Ablex.

Coelho, N. E., Jr., \& Figueiredo, L. C. (2004). Figuras da intersubjetividade na constituição subjetiva. Interações, 9(17), 9-28.

Corsaro, W. A., Molinari, L., Hadley, K. G., \& Sugioka, H. (2003). Keeping and making friends: Italian Children's transition from preschool to elementary school. Social Psychology Quarterly, 66(3), 272-292.

Costa, C. A. (2008). Processo de "abreviação" em relações de bebês com seus pares de idade. (Monografia de conclusão de curso não-publicada). Faculdade de Filosofia, Letras e Ciências Humanas, Universidade de São Paulo, SP.

Costall, A. (1995). Socializing affordances. Theory \& Psychology, 5(4), 467-481.

Darahem, G. C., Silva, A. P. S., \& Costa, N. R. A. (2009). Da teoria do apego à Rede de Significações: Maria Clotilde Rossetti-Ferreira e a Psicologia do Desenvolvimento brasileira. Revista Temas em Psicologia, 17(1), 1-14.
Elmor, L. N. (2009). Recursos comunicativos utilizados por bebês em interação com diferentes interlocutores, durante processo de adaptação à creche: Um estudo de caso. (Dissertação de Mestrado não-publicada). Faculdade de Filosofia, Letras e Ciências Humanas, Universidade de São Paulo, SP.

Fernández-Abascal, E. G. F., Sánchez, F. M., \& Montañés, M. C. (2009). Comunicación gestual y prosódica del bebé. Matronas Profésion, 10(3), 16-18.

Fogel, A. (1992). Movement and communication in human infancy: The social dynamics of development. Human Movement Science, 11, 387-423.

Franchi e Vasconcelos, C. R., Amorim, K. S., Anjos, A. M., \& Rossetti-Ferreira, M. C. (2003). A incompletude como virtude: Interação de bebês na creche. Psicologia: Reflexão $e$ Crítica, 16(2), 293-301.

Gillespie, A. (2010). Position exchange: The social development of agency. New Ideas in Psychology. Advance online publication. doi:10.1016/j.newideapsych.2010.03.004

Lyra, M. C. D. P. (2000). Desenvolvimento de um sistema de relações historicamente construído: Contribuições da comunicação no início da vida. Psicologia: Reflexão e Crítica, 13(2), 257-268.

Lyra, M. C. D. P. (2007). O Modelo EEA: Definições, unidade de análise e possíveis aplicações. Psicologia: Reflexão $e$ Crítica, 20(1), 87-95.

Morett, C. (2007). The effect of shift work on parental interaction with children. Paper presented at Early Childhood Longitudinal Study, Birth Cohort (ECLS-B) First Release Conference: Development from Birth through Age Two. Retrieved September 23, 2009, from http://www.nichd. nih.gov/about/meetings/2007/ecls-b/upload/Morett ECLSB_presentation.pdf

Oliveira, Z. M. R., \& Rossetti-Ferreira, M. C. (1996). Understanding the co-constructive nature of human development: Role coordination in early peer interaction. In E. Voss (Ed.), The structure of learning processes (pp. 177-204). Norwood, NJ: Ablex.

Overton, W. F. (1997). Beyond dichotomy: An embodied active agent for cultural psychology. Culture \& Psychology, 3(3), 315-334.

Pedrosa, M. I., \& Carvalho, A. M. A. (2006). Construction of communication during young children's play. Revista de Etologia, 8, 1-11.

Pino, A. (2005). As marcas do humano. São Paulo, SP: Cortez. Romanelli, G. (1986). Famílias de camadas médias: A trajetória da modernidade. (Tese de Doutorado não-publicada). Faculdade de Filosofia, Letras e Ciências Humanas, Universidade de São Paulo, SP.

Rosenberg, F. (2004). Early child care and educational policies for the developing world. Prospects (Paris), 132, 481-491.

Rossetti-Ferreira, M. C., Amorim, K. S., \& Silva, A. P. S. (2004). Rede de Significações: Alguns conceitos básicos. In M. C. Rossetti-Ferreira, K. S. Amorim, A. P. S. Silva, \& A. N. M. Carvalho (Eds.), Rede de Significações e o estudo do desenvolvimento humano (pp. 23-34). Porto Alegre, RS: Artmed.

Rossetti-Ferreira, M. C., Amorim, K. S., Silva, A. P. S., \& Oliveira, Z. M. R. (2008). Desafios metodológicos na perspectiva da Rede de Significações. Cadernos de Pesquisa, 38, 147-170. 
Rossetti-Ferreira, M. C., Oliveira, Z. M. R., Campos-de-Carvalho, M. I., \& Amorim, K. S. (2011). Peer relations in Brazilian daycare centres: A new focus for early childhood education. In M. Kernan \& E. Singer (Eds.), Peer relationships in early childhood education and care (pp. 7487), London: Routledge Taylor \& Francis Group.

Spink, M. J. (1999). Práticas discursivas e produção de sentidos no cotidiano: Aproximações teóricas e metodológicas. São Paulo, SP: Cortez.

Tomasello, M. (2003). Origens culturais da aquisição do conhecimento humano. São Paulo, SP: Martins Fontes.

Trevarthen, C. (1993). The self born in intersubjectivity: An infant communicating. In U. Neisser (Ed.), The perceived self (pp. 121-173). New York: Cambridge University Press.

Vaitsman, J. (1994). Flexiveis e plurais: Identidade, casamento e família em circunstâncias pós-modernas. Rio de Janeiro, RJ: Rocco.

Wallon, H. (1979). Do ato ao pensamento. Lisboa, Portugal: Moraes.

Yin, K. R. (2005). Estudo de caso. Planejamento e métodos. Porto Alegre, RS: Bookman. 